\title{
Tarefas de Desenvolvimento e História de Vida de Idosos: Análise da Perspectiva de Havighurst
}

\author{
Developmental Tasks and Life History of the Elderly: \\ Analysis of Havighurst's Theory
}

\author{
Eduarda Rezende Freitas*, ${ }^{a}$, Altemir José Gonçalves Barbosa ${ }^{a}$, Natália Scoralick-Lempke ${ }^{b}$ \\ Neide Cordeiro Magalhães ${ }^{a}$, Aline Francine Corrêa Vaz ${ }^{a}$, Christina Nogueira Daret $^{a}$, \\ Fabrícia Souza Peres $^{a} \&$ Mariana Fonseca Carvalho ${ }^{a}$ \\ ${ }^{a}$ Universidade Federal de Juiz de Fora, Juiz de Fora, Minas Gerais, Brasil \\ $\&{ }^{b}$ Faculdade de Pará de Minas, Pará de Minas, Minas Gerais, Brasil
}

\begin{abstract}
Resumo
Para analisar as tarefas de desenvolvimento propostas por Havighurst, 12 idosos foram submetidos ao método de História de Vida. Eles relataram suas histórias em entrevistas grupais e em textos digitalizados. Desconsiderou-se a primeira infância, pois as memórias autobiográficas dessa fase são limitadas. Uma análise de conteúdo temática das verbalizações e dos textos revelou que somente quatro das 40 tarefas das demais fases do curso de vida - meia infância, adolescência, adultez inicial, adultez intermediária e maturidade tardia - não foram mencionadas. As alterações recomendadas para algumas tarefas e a inclusão de uma nova demanda para a maturidade denotam o caráter contextual e histórico delas. Todavia, considera-se que as tarefas de desenvolvimento de Havighurst apresentam evidências de validade ecológica para o contexto brasileiro.

Palavras-chave: Desenvolvimento humano, Havighurst, curso de vida, tarefas de desenvolvimento, idoso.

Abstract

In order to analyze the developmental tasks proposed by Havighurst, 12 elderly people were submitted to the life history method. They told their stories in group interviews and reported them in written texts. Early childhood was disregarded because autobiographical memories of that phase are limited. A thematic content analysis of the verbalizations and texts revealed that only four out of the 40 tasks of the remaining life course phases - middle childhood, adolescence, early adulthood, middle age and later maturity - were not mentioned. The results suggest the need of altering five of the six tasks originally proposed by the author. It is also necessary to include new demands for later maturity which denote the contextual and historical character of the process. Havighurst's developmental tasks showed ecological validity evidence for the Brazilian context, though.

Keywords: Human development, Havighurst, life course, developmental tasks, elderly.
\end{abstract}

Compreender a continuidade durante o curso de vida é um dos principais desafios teórico-metodológicos da Psicologia do Desenvolvimento. Desse modo, com base no método de História de Vida (Silva, Barros, Nogueira, \& Barros, 2007), o presente estudo teve como objetivo identificar, ao longo da vida de idosos, as tarefas de desenvolvimento propostas por Havighurst (1953). Almejou, também, analisar a contemporaneidade e a validade ecoló-

\footnotetext{
* Endereço para correspondência: Instituto de Ciências Humanas, Universidade Federal de Juiz de Fora, Campus Universitário, São Pedro, Juiz de Fora, MG, Brasil 36001970. E-mail: duda 2504@hotmail.com, altgonc@gmail. com,nataliascoralick@yahoo.com.br,neidemag@gmail. com, alinefrancinecorrea@hotmail.com, christinadaret@ ig.com.br, fabricia.peres@hotmail.com e carvalho_marianaf@hotmail.com
}

gica delas. Com base nisso, foi feito, ainda, um exercício que propôs 'novas' tarefas de desenvolvimento ou atualização daquelas formuladas por Havighurst.

Teorias que adotam o construto tarefas de desenvolvimento (TD) propõem que a competência em um período de desenvolvimento serve como base para o êxito futuro (A. Shaffer, Burt, Obradovic, Herbers, \& Masten, 2009). Esse conceito teve origem nos anos 1930, desenvolveu-se na década de 1940 e passou a ser usado mais intensamente durante os anos 1950 (Havighurst, 1956). Inicialmente ligado à área de Educação, o conceito foi influenciado, também, pelas pesquisas psicológicas e sociológicas sobre atitudes e papéis sociais (Havighurst, 1956).

Desde os primórdios, TD têm sido definidas como um conjunto de demandas relacionadas a um determinado período do curso de vida que devem ser cumpridas (Ha- 
vighurst, 1953, 1956) para um desenvolvimento saudável. Quando há falha na realização de alguma delas, o indivíduo pode se tornar infeliz, sofrer desaprovação da sociedade e ter dificuldade na realização das tarefas posteriores (Havighurst, 1953, 1956). Em síntese e fundamentalmente, TD constituem padrões de adaptação que são específicos para um período de desenvolvimento, moldados por expectativas prevalecentes em determinado contexto sociocultural e histórico (Roisman, Masten, Coatsworth, \& Tellegen, 2004).

A expressão TD e seu significado foram sendo fortemente incorporados ao campo da Psicologia do Desenvolvimento ao longo do tempo e, atualmente, é um conceito chave para várias perspectivas que se dedicam à compreensão do desenvolvimento humano (Roisman et al., 2004). Dentre elas, a Life-Span é uma das mais importantes e tem esse conceito como um dos pilares de sua estrutura epistemológica. Baltes (1987) - autor referência dessa concepção - destaca que, para dar sentido à noção de desenvolvimento ao longo da vida, é preciso considerar os tipos de demanda e oportunidades que os indivíduos enfrentam e como eles lidam com elas no decorrer do curso de vida, ou seja, identificar quais são as TD, se e como os indivíduos concretizam-nas. Essa perspectiva propõe, porém, que as TD são fortemente influenciadas por fatores históricos e não normativos, ampliando a concepção de Havighurst que atrela a realização das tarefas a fases de desenvolvimento e idades específicas.

Segundo a perspectiva Life-Span, a sociedade contribui para a construção de cursos de vida, pois prescreve formas apropriadas de comportamento e papéis sociais para as diferentes faixas etárias que são internalizados pelas pessoas e instituições (Neri, 2006). Essas 'formas apropriadas de comportamento e papéis sociais' constituem TD. Assim, o curso de vida pode ser compreendido como um movimento ao longo de estágios, sendo que cada fase possui TD que devem ser concretizadas para que os indivíduos tenham êxito em seu processo desenvolvimental (Havighurst, 1953).

Tanto Havighurst $(1953,1956)$ quanto a perspectiva Life-Span (Baltes, 1987) asseveram que o desenvolvimento não ocorre meramente como produto bruto da maturação, e sim pela associação de aspectos biológicos, sociais e psicológicos. Para Havighurst (1953), os fatores biológicos abrangem, dentre outros, as bases orgânicas do desenvolvimento corporal e do sistema nervoso, a predisposição genética etc. Os fatores sociais incluem, por exemplo, as expectativas da sociedade e do meio cultural. Os psicológicos, por sua vez, compreendem, dentre outros, os processos cognitivos, as percepções, as preferências e as reações emocionais.

À medida que o indivíduo cresce, são desenvolvidos seus recursos físicos e psicológicos, desencadeando demandas e expectativas da sociedade em torno dele. Essas forças internas e externas são responsáveis pela definição de muitas TD. Assim, o surgimento de várias delas ocorre na forma de maturação física, como aprender a andar. Outras decorrem da pressão cultural, como aprender a ler, e há aquelas que advêm dos valores e aspirações do sujeito, como a escolha de uma profissão. Por fim, a maioria surge de combinações de todos esses fatores. (Havighurst, 1953).

Havighurst (1953) propôs que o curso de vida é composto por fases sucessivas, a saber, infância - subdivida em primeira infância e meia infância -, adolescência, adultez - subdividida em inicial e intermediária - e maturidade tardia, demarcadas por limites de idade. A seguir são especificadas algumas características dessas etapas do desenvolvimento com base na obra Human Development and Education (Havighurst, 1953).

As TD a serem cumpridas na infância dependem, essencialmente, da realidade biossocial em que a criança está inserida e da maneira como ela analisa as atividades, já que uma mesma tarefa pode ser considerada de alta ou baixa complexidade por grupos diferentes de crianças. Nesse período, são aprendidas atitudes básicas de confiança, senso de autonomia, além do desenvolvimento da consciência.

Na primeira infância, as TD são divididas em algumas categorias menores. Propõem-se para essa fase as seguintes demandas: 'Aprender a andar'; 'Aprender a ingerir alimentos sólidos'; 'Aprender a falar'; 'Aprender a controlar a eliminação de resíduos do corpo'; 'Aprender as diferenças entre os sexos e a moderar os impulsos sexuais'; 'Aprender a se relacionar emocionalmente com pais, irmãos e outras pessoas'; 'Aprender a distinguir o certo e o errado, desenvolvendo a consciência'; 'Alcançar estabilidade fisiológica'; e 'Formar conceitos simples da realidade física e social'. Já a meia infância é caracterizada por três grandes impulsos desenvolvimentais: (a) a entrada da criança em novos grupos fora do ambiente familiar; (b) o desenvolvimento físico que permite a inserção no mundo dos jogos e a realização de atividades que demandam habilidades neuromusculares; e (c) o desenvolvimento cognitivo que permite a inserção no mundo da lógica, do simbolismo e da comunicação próprios da vida adulta. Dentre outras, constitui TD dessa fase a aquisição de habilidades fundamentais de leitura, escrita e cálculos.

A adolescência é concebida como um período de aquisição de um conjunto de valores morais e éticos que compõem um modelo de homem e cidadão a ser seguido. Esse é um processo que se inicia na infância com a formação de conceitos éticos, tomada de consciência moral e a responsabilidade nas relações com os outros. É um período em que há o desenvolvimento da autonomia pessoal, sendo esperado que o indivíduo se torne independente emocional, financeira e intelectualmente. O grupo de pares assume uma importância maior na vida do indivíduo, tendendo a complementar o círculo familiar e escolar e tendo, muitas vezes, prioridade sobre estas instituições. Estabelecer relações novas e mais maduras com companheiros de idade do mesmo sexo é um exemplo das TD a serem cumpridas nessa etapa. 
Freitas, E. R., Barbosa, A. J. G., Scoralick-Lempke, N., Magalhães, N. C., Vaz, A. F. C., Daret, C. N., Peres, F. S. \& Carvalho, M. F. (2013). Tarefas de Desenvolvimento e História de Vida de Idosos: Análise da Perspectiva de Havighurst.

A próxima fase, adultez inicial - compreendida entre os 18 e 30 anos -, é tida como o período em que mais se têm momentos de aprendizagem. É aquela na qual, geralmente, ocorre o casamento, a primeira gravidez, o primeiro trabalho formal, a compra de uma casa, dentre outros. É um período que pode ser marcado por grande estresse, devido à passagem de uma fase de transição graduada pela idade para uma influenciada pelo status social.

A adultez intermediária, compreendida entre 30 e 55 anos, é considerada como um período da vida que passa muito rapidamente, uma vez que a maioria das pessoas, após essa etapa, sente-se surpresa e com a sensação de ainda estar se preparando para iniciá-la. As alterações biológicas, que não eram percebidas, também começam a ser constatadas.

Ao mesmo tempo em que, nessa fase, homens e mulheres atingem o auge de sua influência sobre a sociedade, esta estabelece demandas específicas sobre eles no que diz respeito à responsabilidade social e cívica. Tradicionalmente, o homem deve desempenhar as funções de marido, provedor e pai, enquanto da mulher são exigidos os papéis de esposa, dona de casa, gerente de família e mãe. Uma das TD apresentadas para essa fase é assumir a responsabilidade cívica e social.

Como nas demais fases do desenvolvimento, na maturidade tardia as pessoas também estão em constante aprendizagem. Assim, nessa fase possuem novas experiências e situações a conhecer, juntamente com TD a cumprir. O ajustamento à aposentadoria e a manutenção de obrigações sociais e cívicas são propostos como tarefas para essa etapa do curso de vida.

$\mathrm{Na}$ maturidade tardia, entretanto, as tarefas vão se diferenciar daquelas relativas às demais fases por serem mais defensivas e preventivas. Tais aspectos vão possibilitar ao indivíduo aprender novas formas de viver - muitas vezes sendo necessário desaprender as formas antigas -, ajustar-se a eventos típicos desse período e lidar melhor com as limitações encontradas, que se tornam evidentes, sobretudo nas esferas física, mental e econômica.

Apesar de Havighurst ter proposto um conjunto de TD para todo o curso de vida há mais de cinco décadas, pesquisas e revisões de literatura recentes ainda as têm usado como base. No entanto, geralmente, isso tem sido feito abrangendo somente uma fase da vida (Krings, Bangerter, Gomez, \& Grob, 2008; Maniar \& Joshi, 2010; Pinquart, Silbereisen, \& Wilesner, 2004) e/ou grupos específicos (Pfeiffer \& Pinquart, 2011).

Pinquart et al. (2004) realizaram um estudo longitudinal com mais de 800 adolescentes para analisar discrepâncias entre o estado real e o desejado para se concretizar as TD nessa fase do curso de vida e sua relação com autoestima. Dentre outras conclusões, os autores asseveram que o êxito nas TD se associa positivamente ao aumento da autoestima.

Buscando verificar a influência das mudanças sócio-históricas nos objetivos pessoais de adultos jovens, Krings et al. (2008) desenvolveram um estudo com 766 suíços, de três coortes diferentes - uma com média de idade de 75 anos, outra de 50 anos e a última com média de idade de 25 anos. A eles foi enviado um questionário contendo perguntas acerca de eventos importantes da vida, objetivos, metas, satisfação com a vida, dentre outras. Os resultados obtidos revelaram que os membros das coortes mais velhas mencionaram metas relacionadas com TD clássicas, enquanto os membros de coortes mais novas indicaram metas mais individualistas e voltadas para a educação. Dessa forma, os autores concluem que os resultados obtidos apoiam a hipótese de que TD variam intergeracionalmente.

Maniar e Joshi (2010) desenvolveram um estudo com idosos indianos com o objetivo de avaliar a influência da televisão em algumas TD da velhice. Os autores elencaram itens relacionados à televisão e verificaram sua alta, média ou baixa influência em determinada tarefa. Observaram, entre outros, uma alta influência da televisão na compra de objetos desnecessários, na promoção de um sentimento de inutilidade nos idosos, dificultando assim a realização da tarefa 'Ajustar-se à aposentadoria e à redução de renda'.

No Brasil, são poucas as publicações acerca das TD propostas por Havighurst (1953). Destacam-se os estudos de Junqueira (2010) e o de Witter (2006). Junqueira (2010), em sua pesquisa com adolescentes usuários de um serviço-escola de orientação profissional, descreve as diversas TD pelas quais os jovens devem passar, enfatizando, sobretudo, aquelas relacionadas com a escolha profissional. Já Witter (2006) faz uma revisão teórica acerca do contexto sócio-histórico em que Havighurst se encontrava ao propor o modelo de TD e discorre sobre elas, enfatizando, sobretudo, aquelas a serem cumpridas pelos idosos.

Faltam, portanto, investigações que analisem todo o conjunto de TD proposto por Havighurst (1953) para o curso de vida. Pelo menos três estratégias distintas podem ser adotadas para pesquisá-las. A primeira e mais evidente diz respeito aos estudos longitudinais, que são demorados e dispendiosos, mas retratariam de modo mais consistente como os indivíduos vivenciam as múltiplas demandas que surgem ao longo da vida. Os estudos transversais constituem uma segunda alternativa e são bastante práticos e econômicos, mas esbarram nas diferenças intergeracionais. Recorrer a idosos e às suas histórias de vida é uma terceira possibilidade, que, da mesma forma que as duas anteriores, possui vantagens e limitações enquanto estratégia de pesquisa, pois, se controla o fator intergeracional, está sujeita ao viés de memória dos participantes. Não obstante suas circunscrições, esse último delineamento constituiu a opção metodológica desta investigação para analisar o conjunto de TD formulado por Havighurst.

\section{Método}

A alternativa metodológica adotada neste estudo foi a História de Vida (Glat, Santos, Pletsch, Nogueira, \& Duque, 2004; Silva et al., 2007). Ela faz uso de uma ou 
mais entrevistas abertas em que os participantes falam livremente sobre sua vida, um determinado período ou aspecto dela, cabendo ao entrevistador aprofundar determinado ponto a partir do discurso do entrevistado (Glat et al., 2004).

\section{Participantes}

Constituíram a amostra deste estudo 12 idosos que participaram de um programa de alfabetização digital realizado na Universidade Federal de Juiz de Fora (UFJF) em 2008 (Scoralick-Lempke, 2009). Para a presente investigação, foram selecionados aqueles que apresentaram maior envolvimento e desempenho nas atividades propostas naquela ocasião, pois as aprendizagens anteriores eram pré-requisitos para o presente estudo. Dentre os participantes desta pesquisa, $66,7 \%(n=8)$ eram do sexo feminino, $75 \%(n=9)$ se declararam brancos e os demais afirmaram ser pardos, $41,6 \%(n=5)$ pertenciam à classe econômica $\mathrm{B} 2$, três $(25 \%)$ ao estrato $\mathrm{C} 1$ e os restantes às classes $\mathrm{A} 1(8,3 \% ; n=1), \mathrm{A} 2(8,3 \% ; n=1)$ e $\mathrm{B} 1(8,3 \%$; $n=1)$. Quanto ao estado civil, houve uma proporção igual $(33,3 \% ; n=4)$ de casados e viúvos; três $(25 \%)$ eram divorciados e um $(8,3 \%)$ era solteiro. A média dos anos estudados foi de $7,83(D P=3,83)$ e a idade média em anos foi de $65,8(D P=4,02)$.

\section{Materiais}

Este estudo teve como materiais um termo de consentimento livre e esclarecido, folhas para registro de observações que continham campos para data, horário, participantes presentes, fase do curso de vida e espaço suficiente para registro contínuo cursivo das atividades, transcrições dos registros efetuados, impressões de textos elaborados pelos participantes e cópias impressas das TD. Além disso, utilizaram-se, evidentemente, hardwares (computadores etc.) e softwares (editor de texto etc.) para as oficinas de informática.

\section{Procedimento}

Após aprovação por um comitê de ética, efetuou-se contato telefônico com os idosos. Aqueles que, inicialmente, aceitaram participar da pesquisa, foram distribuídos aleatoriamente em dois grupos. Na primeira reunião, assinaram o Termo de Consentimento Livre e Esclarecido para confirmar a participação na investigação.

Foram realizados 20 encontros, análogos a um grupo focal, dois por semana, com duração de, aproximadamente, 90 minutos cada, perfazendo uma carga horária total de 30 horas. Eles aconteceram entre os meses de maio e setembro do ano de $2009 \mathrm{em}$ um laboratório de pesquisa, com condições ambientais suficientes para assegurar conforto e confidencialidade. Foram conduzidos por uma psicóloga, com a colaboração de graduandos de Psicologia, sendo que dois deles auxiliaram nas entrevistas e no ensino de informática e três se incumbiram do registro cursivo dos discursos dos idosos.
Nos primeiros 40 minutos de cada encontro, fizeram-se, em grupo, as entrevistas de História de Vida e, nos 50 minutos restantes, foram realizadas, também em grupo, oficinas de informática, provendo situações de aprendizagem para que os idosos tivessem conhecimentos para criar textos, editar imagens e vídeos, navegar na internet e criar um blog pessoal registrando suas histórias de vida. Ressalta-se que, na etapa final de cada encontro, dos idosos demandava-se criar 'memórias digitais' (textos, fotos, depoimentos etc.) sobre suas histórias de vida. Assevera-se, ademais, que os procedimentos foram realizados de forma equivalente e paralelamente nos dois grupos.

\section{Análise dos Dados}

Os registros dos observadores e somente os textos produzidos pelos próprios participantes sobre cada fase do curso de vida constituíram as fontes de dados deste estudo. Eles foram submetidos a uma análise de conteúdo temática, sendo que as TD propostas por Havighurst (1953) constituíram eixos temáticos previamente definidos, mas existia a possibilidade de se incluir novos temas, isto é, novas TD. Ressalta-se que a primeira infância não foi considerada na análise, uma vez que ela abrange demandas desenvolvimentais que nem sempre possuem 'memórias' (p.ex., 'ingerir alimentos sólidos').

Munidos com uma folha que descrevia as TD de cada fase de vida, dois colaboradores com conhecimentos sobre análise de conteúdo procuraram identificá-las nos textos elaborados pelos participantes e nos registros realizados pelos observadores. Esse procedimento foi submetido à revisão de, pelo menos, um juiz. Em caso de discordância entre analistas e juízes, chegou-se a um consenso dialogado. Ainda que tenha recorrido à estatística descritiva, este estudo é, portanto, essencialmente qualitativo.

\section{Resultados}

Quanto à meia infância (Tabela 1), oito $(88,88 \%)$ das nove TD propostas por Havighurst (1953) apareceram nas histórias de vida de um ou mais participantes. 'Aprender habilidades físicas necessárias para brincadeiras' $(n=12 ; 100 \%)$ e 'Alcançar independência pessoal' $(n=8$; $66,66 \%$ ) parecem ser as mais presentes nas histórias de vida. 'Desenvolver conceitos necessários para a vida cotidiana' foi identificada em apenas um $(8,33 \%)$ idoso e 'Construir atitudes sadias em relação ao próprio corpo' não foi relatada.

Considerou-se que somente duas das nove tarefas propostas por Havighurst (1953), a saber, 'Aprender habilidades físicas necessárias para brincadeiras' e 'Apropriar-se do papel social masculino e feminino', demandam alteração em sua forma original. Sugere-se que elas passem a ser enunciadas da seguinte forma: 'Aprender habilidades necessárias para brincadeiras' e 'Desenvolver papéis sociais de gênero'. 
Freitas, E. R., Barbosa, A. J. G., Scoralick-Lempke, N., Magalhães, N. C., Vaz, A. F. C., Daret, C. N., Peres, F. S. \& Carvalho, M. F. (2013). Tarefas de Desenvolvimento e História de Vida de Idosos: Análise da Perspectiva de Havighurst.

Tabela 1

Tarefas de Desenvolvimento da Meia Infância

\begin{tabular}{|c|c|c|c|}
\hline Tarefa Original & Exemplo & Atualização & Ocorrência \\
\hline $\begin{array}{l}\text { Aprender habilidades } \\
\text { físicas necessárias } \\
\text { para brincadeiras }\end{array}$ & $\begin{array}{l}\text { "Brincávamos muito no quintal de nossa casa } \\
\text { ou na rua". }\end{array}$ & $\begin{array}{l}\text { Aprender } \\
\text { habilidades } \\
\text { necessárias para } \\
\text { brincadeiras }\end{array}$ & $\begin{array}{c}n=12 \\
100 \%\end{array}$ \\
\hline $\begin{array}{l}\text { Alcançar independência } \\
\text { pessoal }\end{array}$ & $\begin{array}{l}\text { "Com idade de } 7 \text { anos já tinha minhas obrigações: } \\
\text { varrer a casa, socar arroz no pilão, debulhar milho, } \\
\text { tocar as vacas para o pasto, e buscar nas manhãs de } \\
\text { geada que era pesado...". }\end{array}$ & ------- & $\begin{array}{l}n=8 \\
66,66 \%\end{array}$ \\
\hline $\begin{array}{l}\text { Apropriar-se do papel } \\
\text { social masculino } \\
\text { e feminino }\end{array}$ & $\begin{array}{l}\text { "Eu, Dora e Selma tivemos a ideia de brincar de } \\
\text { casinha. Cada uma tinha sua casa... nossas bonecas } \\
\text { nossas filhas, fazia mamadeira, o banho delas, hora } \\
\text { do colégio e passear com elas". }\end{array}$ & $\begin{array}{l}\text { Desenvolver } \\
\text { papéis sociais } \\
\text { de gênero }\end{array}$ & $\begin{array}{c}n=7 \\
58,33 \%\end{array}$ \\
\hline $\begin{array}{l}\text { Desenvolver habilidades } \\
\text { fundamentais de leitura, } \\
\text { escrita e cálculos }\end{array}$ & $\begin{array}{l}\text { "Tomava todos os dias a tabuada, verbos e os pontos } \\
\text { que mandava estudar Eu sempre tirava notas boas". }\end{array}$ & ------- & $\begin{array}{c}n=7 \\
58,33 \%\end{array}$ \\
\hline $\begin{array}{l}\text { Aprender a conviver } \\
\text { com companheiros } \\
\text { da mesma idade }\end{array}$ & $\begin{array}{l}\text { "Pela manhã, ir à escola e, à tarde, encontrar os } \\
\text { amigos na rua". }\end{array}$ & ------- & $\begin{array}{c}n=6 \\
50 \%\end{array}$ \\
\hline $\begin{array}{l}\text { Desenvolver a moral } \\
\text { e os valores }\end{array}$ & $\begin{array}{l}\text { "Ainda morava conosco meus avós paternos e uma } \\
\text { tia solteira, professora que nos ajudaram bastante na } \\
\text { criação, principalmente na educação, na formação } \\
\text { de caráter". }\end{array}$ & ------- & $\begin{array}{c}n=6 \\
50 \%\end{array}$ \\
\hline $\begin{array}{l}\text { Desenvolver atitudes } \\
\text { em relação a grupos } \\
\text { sociais e instituições }\end{array}$ & $\begin{array}{l}\text { "Nós, as crianças, ficávamos lá no meio daquele } \\
\text { povo, muito felizes, participando da festa". }\end{array}$ & ------- & $\begin{array}{c}n=4 \\
33,33 \%\end{array}$ \\
\hline $\begin{array}{l}\text { Desenvolver conceitos } \\
\text { necessários para a vida } \\
\text { cotidiana }\end{array}$ & $\begin{array}{l}\text { Meu pai trabalhava na estrada de ferro ... de } \\
\text { propriedade do governo inglês, que também estava } \\
\text { em fase de guerra, solicitou uma licença do seu } \\
\text { trabalho ... tendo conseguido ótimo emprego ... } \\
\text { nossa vida mudou muito, pois ganhava muito bem ... }\end{array}$ & ------- & $\begin{array}{l}n=1 \\
8,33 \%\end{array}$ \\
\hline $\begin{array}{l}\text { Construir atitudes sadias } \\
\text { em relação ao próprio } \\
\text { corpo }\end{array}$ & ------- & ------- & ------- \\
\hline
\end{tabular}

Todas as dez TD propostas por Havighurst (1953) para a adolescência apareceram nas histórias de vida, sendo citadas por, pelo menos, dois idosos (Tabela 2). 'Obter garantias de independência econômica' $(n=9$; $75 \%$ ), 'Estabelecer relações novas e mais maduras com companheiros de mesma idade de ambos os sexos' $(n=8$; $66,7 \%)$ e 'Desejar alcançar um comportamento socialmente responsável' ( $n=7 ; 58,3 \%)$ foram mencionadas por mais da metade dos participantes. Ainda que não seja adequado fazer inferências, é possível afirmar que as TD 'Aceitar a aparência física e usar o corpo de forma eficaz' ( $n=2$; $16,6 \%$ ), 'Alcançar um papel social masculino ou feminino' $(n=4 ; 33,2 \%)$ e 'Desenvolver habilidades intelectuais e conceitos necessários para a competência cívica' $(n=4$; $33,2 \%$ ) foram pouco frequentes.

Destaca-se que, para a adolescência, considerou-se necessário alterar uma das TD proposta por Havighurst (1953). Recomenda-se que 'Alcançar um papel social masculino ou feminino' seja alterada para 'Alcançar um papel social de gênero'. 
Psicologia: Reflexão e Crítica, 26(4), 809-819.

Tabela 2

Tarefas de Desenvolvimento da Adolescência

\begin{tabular}{|c|c|c|c|}
\hline Tarefa Original & Exemplo & Atualização & Ocorrência \\
\hline $\begin{array}{l}\text { Obter garantias de independência } \\
\text { econômica }\end{array}$ & $\begin{array}{l}\text { “. . com } 13 \text { para } 14 \text { anos assumi o emprego do } \\
\text { meu pai, pois precisava de alguém para sustentar } \\
\text { a familia". }\end{array}$ & ------- & $\begin{array}{c}n=9 \\
75 \%\end{array}$ \\
\hline $\begin{array}{l}\text { Estabelecer relações novas e mais } \\
\text { maduras com companheiros de } \\
\text { mesma idade de ambos os sexos }\end{array}$ & $\begin{array}{l}\text { "Gostávamos muito de passear na Rua Halfeld } \\
\text { para ver os jovens rapazes e paquerar os possíveis } \\
\text { candidatos a namorados". }\end{array}$ & ------- & $\begin{array}{l}n=8 \\
66,7 \%\end{array}$ \\
\hline $\begin{array}{l}\text { Desejar alcançar um } \\
\text { comportamento socialmente } \\
\text { responsável }\end{array}$ & $\begin{array}{l}\text { "Quando completei } 18 \text { anos, fui para o Exército, isso } \\
\text { em 1938". }\end{array}$ & ------- & $\begin{array}{l}n=7 \\
58,3 \%\end{array}$ \\
\hline $\begin{array}{l}\text { Adquirir um conjunto de valores } \\
\text { e um sistema ético como um guia } \\
\text { para o comportamento }\end{array}$ & $\begin{array}{l}\text { "Gostava de farrear, mas sempre respeitei os outros". } \\
\text { "Antigamente o único medo dos pais era que a gente } \\
\text { perdesse a virgindade. Eu era estabanada, mas era } \\
\text { ajuizada. As pessoas podiam ficar faladas". }\end{array}$ & ------- & $\begin{array}{c}\mathrm{n}=6 \\
50 \%\end{array}$ \\
\hline $\begin{array}{l}\text { Preparar-se e selecionar uma } \\
\text { ocupação }\end{array}$ & $\begin{array}{l}\text { "Recordo com saudades do meu tempo de estudante, } \\
\text { de meus professores e de meus colegas. Fiz dois } \\
\text { cursos: Auxiliar de Escritório e Formação de } \\
\text { Professor". }\end{array}$ & ------- & $\begin{array}{c}n=6 \\
50 \%\end{array}$ \\
\hline $\begin{array}{l}\text { Preparar-se para o matrimônio } \\
\text { e a vida familiar }\end{array}$ & $\begin{array}{l}\text { “. . fiquei noiva muito nova, com } 16 \text { anos, para } \\
\text { constituir família...". }\end{array}$ & ------- & $\begin{array}{c}n=6 \\
50 \%\end{array}$ \\
\hline $\begin{array}{l}\text { Alcançar a independência } \\
\text { emocional dos pais e outros } \\
\text { adultos }\end{array}$ & $\begin{array}{l}\text { "Eu era doido pra sair de casa. Sempre fui muito } \\
\text { reprimido. Meu pai controlava tudo. .. Quando fui } \\
\text { para o Rio de Janeiro servir a Marinha, me senti } \\
\text { bem mais livre". }\end{array}$ & ------ & $\begin{array}{l}n=5 \\
41,6 \%\end{array}$ \\
\hline $\begin{array}{l}\text { Alcançar um papel social } \\
\text { masculino ou feminino }\end{array}$ & $\begin{array}{l}\text { "Eu ficava em casa ajudando minha mãe. Quando } \\
\text { eu tinha } 12 \text { anos, a minha mãe saía e eu tinha que } \\
\text { cozinhar, lavar e cuidar dos meus irmãos". }\end{array}$ & $\begin{array}{l}\text { Alcançar um } \\
\text { papel social } \\
\text { de gênero. }\end{array}$ & $\begin{array}{l}n=4 \\
33,2 \%\end{array}$ \\
\hline $\begin{array}{l}\text { Desenvolver habilidades } \\
\text { intelectuais e conceitos necessários } \\
\text { para a competência cívica }\end{array}$ & $\begin{array}{l}\text { "Se eu fiz um primeiro ano bem feito, era porque eu } \\
\text { tinha obrigação". }\end{array}$ & ------- & $\begin{array}{l}n=4 \\
33,2 \%\end{array}$ \\
\hline $\begin{array}{l}\text { Aceitar a aparência física e usar } \\
\text { o corpo de forma eficaz }\end{array}$ & $\begin{array}{l}\text { "No final daquele ano foi formado um batalhão } \\
\text { para ir para o Canal de Suez. Tentei ir, porém não } \\
\text { consegui por não ter altura". }\end{array}$ & ------- & $\begin{array}{l}n=2 \\
16,6 \%\end{array}$ \\
\hline
\end{tabular}

A Tabela 3 descreve as TD da adultez inicial. Das oito possíveis, somente 'Assumir responsabilidade cívica' não apareceu nas histórias de vida dos idosos e 'Formar um grupo social comum ao casal' foi relatada por menos de $50 \%$ dos participantes $(n=5 ; 41,7 \%)$. As outras demandas desenvolvimentais dessa fase do curso de vida tiveram escores mais expressivos, sendo que merecem destaque 'Aprender a conviver com o companheiro' e 'Escolher um companheiro', que foram identificadas nos discursos de dez (83,3\%) idosos.

Identificou-se, também para a adultez inicial, a necessidade de revisar algumas TD propostas por Havighurst
(1953). Sugere-se que 'Ingressar numa profissão' seja alterada para 'Ingressar numa profissão e mantê-la'. Recomenda-se, ademais, que os verbos 'adaptar' e 'aceitar e adaptar' sejam substituídos, respectivamente, por 'lidar com' e 'desenvolver estratégias de enfrentamento quanto', como exposto na Tabela 3.

Havighurst (1953) propôs sete TD para a adultez intermediária (Tabela 4), sendo que seis delas apareceram nas histórias dos idosos. A única que não foi identificada nos discursos foi 'Aceitar e se adaptar às mudanças fisiológicas da meia idade'. 
Freitas, E. R., Barbosa, A. J. G., Scoralick-Lempke, N., Magalhães, N. C., Vaz, A. F. C., Daret, C. N., Peres, F. S. \& Carvalho, M. F. (2013). Tarefas de Desenvolvimento e História de Vida de Idosos: Análise da Perspectiva de Havighurst.

Tabela 3

Tarefas de Desenvolvimento da Adultez Inicial

\begin{tabular}{|c|c|c|c|}
\hline Tarefa Original & Exemplo & Atualização & Ocorrência \\
\hline $\begin{array}{l}\text { Aprender a conviver } \\
\text { com o companheiro }\end{array}$ & "Eu não trabalhava fora, meu marido não deixava". & ------- & $\begin{array}{l}n=10 \\
83,3 \%\end{array}$ \\
\hline $\begin{array}{l}\text { Escolher um } \\
\text { companheiro }\end{array}$ & $\begin{array}{l}\text { "Casei com um simpático carioca, numa cerimônia belíssima. . } \\
\text {. e meu pai caprichou na festa". }\end{array}$ & ------- & $\begin{array}{l}n=10 \\
83,3 \%\end{array}$ \\
\hline Constituir uma família & $\begin{array}{l}\text { "Logo engravidei, passei muito mal . . . nasceu meu bebê um } \\
\text { menino muito sadio. Eu e meu marido ficamos muito satisfeitos, } \\
\text { queríamos menino". }\end{array}$ & ------- & $\begin{array}{c}n=9 \\
75 \%\end{array}$ \\
\hline Gerenciar o lar & $\begin{array}{l}\text { "Nem móveis tinha direito. A primeira geladeira que eu tive era } \\
\text { de porta de madeira, porém atendia às necessidades e nunca me } \\
\text { deu trabalho. Com o passar dos tempos fomos pondo as coisas } \\
\text { em seus devidos lugares". }\end{array}$ & ------- & $\begin{array}{c}n=9 \\
75 \%\end{array}$ \\
\hline $\begin{array}{l}\text { Ingressar numa } \\
\text { profissão }\end{array}$ & $\begin{array}{l}\text { "Assim aconteceu o primeiro momento da minha carreira, } \\
\text { aprendi a trabalhar com topografia, recebi classificação de } \\
\text { nivelador". }\end{array}$ & $\begin{array}{l}\text { Ingressar } \\
\text { numa profissão } \\
\text { e mantê-la }\end{array}$ & $\begin{array}{c}n=9 \\
75 \%\end{array}$ \\
\hline Criar os filhos & "Fiz tudo para proporcionar a eles uma infância tranquila". & ------- & $\begin{array}{l}n=7 \\
58,3 \%\end{array}$ \\
\hline $\begin{array}{l}\text { Formar um grupo so- } \\
\text { cial comum ao casal }\end{array}$ & $\begin{array}{l}\text { "Moramos naquela cidade por } 2 \text { anos. Fizemos muitas e boas } \\
\text { amizades". }\end{array}$ & ------- & $\begin{array}{l}n=5 \\
41,7 \%\end{array}$ \\
\hline $\begin{array}{l}\text { Assumir responsabili- } \\
\text { dade cívica }\end{array}$ & ------ & ------- & ------- \\
\hline
\end{tabular}

Tabela 4

Tarefas de Desenvolvimento da Adultez Intermediária

\begin{tabular}{|c|c|c|c|}
\hline Tarefa Original & Exemplo & Atualização & Ocorrência \\
\hline $\begin{array}{l}\text { Ajudar os filhos a se tor- } \\
\text { narem adultos responsá- } \\
\text { veis e felizes }\end{array}$ & $\begin{array}{l}\text { "Batizamos com o nome de Emerson. Ele nos deu } \\
\text { muita alegria, nos preocupava com a educação } \\
\text { dele. Época do colégio, e colocamos em outros } \\
\text { cursos para o bem dele". }\end{array}$ & ------- & $\begin{array}{l}n=5 \\
41,7 \%\end{array}$ \\
\hline $\begin{array}{l}\text { Estabelecer e manter } \\
\text { um padrão de vida } \\
\text { econômico }\end{array}$ & $\begin{array}{l}\text { "Eu ficava no vai e vem todo fim de semana. Fiquei } \\
\text { nessa luta durante uns seis meses até que consegui } \\
\text { pôr as finanças em dia...". }\end{array}$ & ------- & $\begin{array}{l}n=4 \\
33,3 \%\end{array}$ \\
\hline $\begin{array}{l}\text { Realizar atividades } \\
\text { de lazer de adultos }\end{array}$ & $\begin{array}{l}\text { "Fiz diversas viagens aéreas e terrestres, conheci } \\
\text { todas as capitais do nordeste e um pouco do sul". }\end{array}$ & ------- & $\begin{array}{l}n=4 \\
33,3 \%\end{array}$ \\
\hline $\begin{array}{l}\text { Adaptar-se às mudanças } \\
\text { do companheiro ao longo } \\
\text { do relacionamento }\end{array}$ & $\begin{array}{l}\text { "Trabalhei em fábrica... depois parei para cuidar do } \\
\text { marido". }\end{array}$ & $\begin{array}{l}\text { Lidar com as mudanças } \\
\text { do companheiro ao lon- } \\
\text { go do relacionamento }\end{array}$ & $\begin{array}{c}n=3 \\
25 \%\end{array}$ \\
\hline $\begin{array}{l}\text { Alcançar responsabilida- } \\
\text { de social e cívica adultas }\end{array}$ & $\begin{array}{l}\text { "Convivendo com a cidade, passei a fazer parte do } \\
\text { Lions Clube, no qual fui presidente". }\end{array}$ & ------- & $\begin{array}{c}n=3 \\
25 \%\end{array}$ \\
\hline $\begin{array}{l}\text { Adaptar-se ao envelheci- } \\
\text { mento dos pais }\end{array}$ & "Fiquei muito triste com a morte de minha mãe". & $\begin{array}{l}\text { Lidar com o envelheci- } \\
\text { mentodos pais }\end{array}$ & $\begin{array}{l}n=1 \\
8,33 \%\end{array}$ \\
\hline $\begin{array}{l}\text { Aceitar e se adaptar } \\
\text { às mudanças fisiológicas } \\
\text { da meia idade }\end{array}$ & ------- & $\begin{array}{l}\text { Desenvolver estratégias } \\
\text { de enfrentamento quan- } \\
\text { to às mudanças fisioló- } \\
\text { gicas da meia idade }\end{array}$ & ------- \\
\hline
\end{tabular}


Apesar de aparecerem nas histórias de vida dos idosos, as TD da adultez intermediária não apresentaram escores expressivos, sendo que nenhuma foi identificada em, pelo menos, $50 \%$ dos discursos. Não obstante, 'Ajudar os filhos a se tornarem adultos responsáveis e felizes', presente no relato de 41,7\% $(n=5)$ dos participantes, 'Estabelecer e manter um padrão de vida econômico' e 'Realizar ativida- des de lazer de adultos', ambas citadas por quatro $(33,3 \%)$ idosos, merecem menção.

Quanto à maturidade tardia (Tabela 5), observou-se, por um lado, que quatro $(57,1 \%)$ TD foram citadas por, pelo menos, 83,3\% $(\mathrm{n}=10)$ dos participantes. Por outro lado, 'Estabelecer arranjos físicos satisfatórios para viver bem a velhice' não foi mencionada.

Tabela 5

Tarefas de Desenvolvimento da Maturidade Tardia

\begin{tabular}{ll}
\hline Tarefa Original & Exemplo \\
\hline Ajustar-se às mudanças & "Sei que o envelhecimento é um processo \\
físicas e de saúde (ajustar- & biológico, que pode ser controlado, por isso \\
se ao decréscimo de força & procuro ocupar minha mente com hábitos \\
física e saúde) & saudáveis. Faço caminhada, boas leituras, uma \\
& alimentação controlada, cuido de minha saúde \\
& com exames uma vez ao ano".
\end{tabular}

Ajustar-se à aposentadoria e à redução de renda

Ajustar-se à morte do esposo (a)

Estabelecer filiação a um grupo de pessoas (idosas)

Manter obrigações sociais e cívicas

Estabelecer arranjos físicos satisfatórios para viver bem a velhice
"Estou aposentada, tenho meu salário que me garante muita tranquilidade e me permite ser independente e fazer as coisas que eu quero".

"Hoje não tenho mais meu marido, mas tenho meus filhos, noras e neto".

"Na igreja São Mateus eu participo do Curso Bíblico, de um grupo da Legião de Maria e da Pastoral do Batismo. Essas atividades me proporcionam muitos conhecimentos e amizades maravilhosas".

"Me sinto responsável pela educação dos meus netos. Tenho muita preocupação com isso".
Atualização

Lidar com as mudanças

relacionadas à saúde $(\mathrm{p}$.

ex. lidar com o decréscimo

de força física, alterações

cognitivas e na

sexualidade)

Lidar com a aposentadoria

$n=10$;

$83,3 \%$

Desenvolver estratégias

$n=4$;

de enfrentamento para $\quad 33,2 \%$

lidar com a morte

Estar filiado a um grupo

$n=11$;

social

$91,7 \%$

Engajar-se em

$n=1$;

compromissos sociais

$8,3 \%$ e cívicos

Manter e estabelecer laços familiares e de amizade $n=12$;

$100 \%$ dos anos e no meio de uma família privilegiada e querida. Minha mãe aos 91 anos, as quatro irmãs maravilhosas e preciosos sobrinhos $e$ sobrinhos netos me deixam plena no campo afetivo e sentimental.

Identificou-se a necessidade de acrescentar a tarefa 'Manter e estabelecer laços familiares e de amizade' às seis propostas por Havighurst (1953) para essa fase. Além de relevante, essa demanda desenvolvimental foi apresentada por todos os idosos $(n=12,100 \%)$.

Mais do que nas demais etapas do curso de vida, verificou-se, também, a necessidade de alterar as TD propostas por Havighurst (1953). Recomenda-se a alteração de cinco das seis tarefas originalmente propostas pelo autor. As sugestões aparecem na Tabela 5.

\section{Discussão}

Ao considerar os resultados, há que se destacar, inicialmente, que o fato de algumas TD propostas por Havighurst (1953) não terem aparecido ou terem baixa frequência nas histórias de vida dos idosos não significa que elas não tenham sido vivenciadas e cumpridas com maior ou menor êxito. O método de História de Vida é um processo de rememorar, de revisitar a vida do sujeito (Silva et al., 2007). Nele, as pessoas são ativas, recorrem à memória, 
Freitas, E. R., Barbosa, A. J. G., Scoralick-Lempke, N., Magalhães, N. C., Vaz, A. F. C., Daret, C. N., Peres, F. S. \& Carvalho, M. F. (2013). Tarefas de Desenvolvimento e História de Vida de Idosos: Análise da Perspectiva de Havighurst.

mais especificamente à memória autobiográfica, que é "a síntese e a referência de nossas histórias de vida" (Gauer \& Gomes, 2008, p. 507) e reconstrói mais do que representa fielmente as vivências (Josselson, 2009). Portanto, selecionam aspectos mais significativos de suas histórias. Desse modo, é possível afirmar que as TD identificadas são, provavelmente, as mais salientes e não necessariamente as que foram vivenciadas pelos idosos.

Os trechos dos discursos dos idosos apresentados em Resultados denotam o quão proeminentes as tarefas foram para eles. De modo geral, os participantes parecem revelar que elas foram cumpridas com êxito. Por se tratar de uma amostra de idosos com características de envelhecimento bem sucedido, isso era esperado. Cumpre retomar que, para Havighurst (1953, 1956), o fracasso na concretização de algumas delas pode fazer com que o indivíduo se torne infeliz, sofra desaprovação da sociedade e tenha dificuldade no atendimento das demandas posteriores. Pesquisas mais recentes, como a de Pinquart et al. (2004), têm corroborado isso, pois o êxito nas TD se associou positivamente ao aumento da autoestima.

Exceto na adultez intermediária, algumas tarefas se destacaram por obter ocorrências bastante expressivas. Na meia infância, merece realce a tarefa 'Aprender habilidades necessárias para brincadeiras'. As brincadeiras contribuem para o desenvolvimento físico, social, intelectual e emocional da criança (D. R. Shaffer \& Kipp, 2012) e constituem sua principal atividade (Papalia, Olds, \& Feldman, 2010). Essas características, aliadas ao caráter lúdico inerente ao brincar, são responsáveis, provavelmente, pela saliência dessa tarefa desenvolvimental na memória biográfica dos idosos.

A adolescência, por sua vez, é um período em que o sujeito é convidado a participar ativamente da construção do seu projeto de vida (Martins, Trindade, \& Almeida, 2003) e de sua identidade. Em consonância, as TD que abrangem a independência econômica, o estabelecimento de um grupo de amigos, a responsabilidade e a formação de valores se destacaram entre os participantes. A tarefa 'Obter garantias de independência econômica' foi a que obteve a maior ocorrência. Cabe destacar que, na atualidade, o cumprimento dessa tarefa tem acontecido principalmente na adultez inicial (Pimenta, 2007), sobretudo entre os jovens de classes sociais mais favorecidas.

$\mathrm{Na}$ adultez inicial, as TD relacionadas com a formação e manutenção de uma família, como 'Escolher um companheiro' e 'Aprender a conviver com o companheiro', foram as mais citadas pelos participantes. Embora haja atualmente novas formas de organização familiar e visões relativas ao casamento, como o aumento na idade média das mulheres ao se casarem (Instituto Brasileiro de Geografia e Estatística [IBGE], 2010), a escolha do cônjuge e a manutenção da relação com ele ainda são tarefas contemporâneas. Os relacionamentos pessoais contribuem para a consolidação da identidade do sujeito e trazem consigo o reconhecimento social (Magalhães \& Gomes, 2005).
$\mathrm{Na}$ adultez intermediária, como destacado anteriormente, nenhuma tarefa obteve uma ocorrência expressiva entre os participantes. Assim, parece que as demandas dessa etapa foram menos salientes nas histórias de vida dos idosos. Ressalta-se que, apesar disso, elas não são menos importantes do que as demais TD elaboradas para as outras fases da vida.

TD da maturidade tardia relacionadas à manutenção de laços sociais e adaptação às mudanças na saúde foram as mais mencionadas pelos idosos. De acordo com Baltes (1987), uma das características do envelhecimento saudável é o engajamento ativo na vida, que inclui a participação e a interação social. Esse estilo de vida coaduna com as características da amostra deste estudo, constituída predominantemente por idosos saudáveis. Isso, entretanto, não invalida a necessidade de adaptação às diversas mudanças típicas e inevitáveis que ocorrem nessa fase da vida (Baltes, 1987).

Observou-se, também, que algumas das TD propostas por Havighurst (1953) podem ser 'atualizadas'. As demandas desenvolvimentais da adultez intermediária e, principalmente, da velhice são as que mais necessitam de atualizações. Parcela expressiva das alterações sugeridas diz respeito ao uso dos verbos ajustar e adaptar, que, para os Autores, devem ser substituídos pelos verbos lidar, desenvolver ou outros que, ao contrário daqueles, denotem o papel ativo das pessoas na 'gestão de suas vidas' (Freund, 2001), enfatizem menos as forças externas e expressem mais a combinação de forças biológicas, psicológicas e sociais que atuam na concretização das $\mathrm{TD}$, como proposto por Havighurst (1953).

Além disso, as atualizações sugeridas buscam destacar o processo de ganhos e perdas que, para a perspectiva Life-Span (Baltes, 1987), caracteriza o desenvolvimento humano. Consideraram-se, ademais, as mudanças sociais e culturais hodiernas que fazem com que os idosos: não tenham, necessariamente, perdas de poder aquisitivo devido à aposentadoria (p.ex., sistemas de previdência privada, seguridade social); não se filiem somente a grupos de idosos, estabelecendo relações intergeracionais, incluindo participação ativa na criação dos netos; não tenham 'obrigações' sociais e cívicas, mas sim 'compromissos' sociais e cívicos que demandam engajamento (Witter, 2006).

O aumento da expectativa de vida, a maior valorização social, a melhoria da qualidade vida, as mudanças nos papéis familiares e comunitários, a maior participação social dentre outras características contemporâneas da velhice, têm feito com que os idosos não só mantenham os laços familiares e de amizade constituídos ao longo do curso de vida, mas, também, estabeleçam novos relacionamentos, incluindo casamentos e grupos de pares que se reúnem para atividades educacionais e de lazer. Desse modo, recomendou-se a inclusão de uma 'nova' tarefa desenvolvimental para essa fase do curso de vida - 'Manter e estabelecer laços familiares e de amizade' -, que enfatiza as demandas de desenvolvimento social propostas ao idoso atualmente. 
Foram recomendadas, também, atualizações para TD da meia infância, adolescência e adultez inicial. As alterações almejam contemplar características sociais e culturais contemporâneas. Reitera-se que as demandas desenvolvimentais traduzem expectativas predominantes em um determinado contexto sociocultural e histórico (Roisman et al., 2004) e, portanto, não são ad eternum, devendo ser alvo de revisões. Krings et al. (2008) verificaram em seu estudo com três coortes diferentes que as TD variaram intergeracionalmente.

Dentre as TD sugeridas para a meia infância, 'Aprender habilidades físicas necessárias para brincadeiras' teve sua nomenclatura alterada para 'Aprender habilidades necessárias para brincadeiras'. Tal atualização contempla outras habilidades, além das físicas, que são importantes para a participação das crianças em atividades lúdicas, como, por exemplo, a criatividade, as habilidades motoras, a coordenação e a capacidade de abstração (D. R. Shaffer \& Kipp, 2012). A TD 'Apropriar-se do papel social masculino e feminino' também foi atualizada para 'Desenvolver papéis sociais de gênero', uma vez que o atual conceito de gênero enfatiza a influência de processos sociais e culturais, sendo mais abrangente do que a antiga concepção de 'masculino ou feminino', pautada essencialmente na biologia (Perucchi, 2009).

A alteração da tarefa 'Alcançar um papel social masculino ou feminino', a ser realizada na adolescência, para 'Alcançar um papel social de gênero' destaca, também, a importância do contexto sociocultural na definição dos papéis esperados para homens e mulheres. Havighurst (1953) salienta que o sucesso nessa tarefa resultaria, dentre outros, no desenvolvimento de sentimentos heterossexuais. Em virtude das atuais concepções sobre os papéis de gênero, sugere-se a modificação no conteúdo dessa tarefa, ressaltando que seu sucesso resulta no desenvolvimento de sentimentos afetivos, não unicamente heterossexuais.

A única tarefa da adultez inicial que sofreu alteração foi 'Ingressar numa profissão', que adquiriu a forma 'Ingressar numa profissão e se manter no mercado de trabalho'. Atualmente, a vida laboral apresenta características muito distintas das observadas em meados do século passado, desafiando cada vez mais os trabalhadores que são levados a terem educação continuada, a se especializarem e, principalmente, a lidarem com instabilidades decorrentes das mudanças nos modos de produção.

\section{Considerações Finais}

É possível afirmar, ainda que parcimoniosamente, que tanto o conceito quanto as TD propostas por Havighurst apresentam, ainda hoje, evidências de validade ecológica para o contexto brasileiro. Reitera-se que o autor propôs o conjunto de tarefas que constituiu o foco desta investigação há mais de 50 anos, em um momento histórico muito distinto do atual.

Há que se retomar, como proposto pela perspectiva Life-Span (Baltes, 1987), que as TD têm caráter histórico, não normativo. Isso ficou evidenciado, por exemplo, na necessidade de efetuar inclusões e alterações de TD assinaladas neste estudo e na constatação de, por exemplo, Maniar e Joshi (2010) de que tecnologias, como a TV, podem influenciar o êxito em algumas demandas desenvolvimentais.

Ao generalizar os resultados deste estudo, é preciso, porém, considerar as limitações metodológicas dele, especialmente aquelas relacionadas à amostra, que é circunscrita quantitativa e qualitativamente e, como abordado anteriormente, baseiam-se no método de História de Vida, que, da mesma forma que outras estratégias metodológicas, possui limitações. Além das limitações inerentes a esse delineamento (p.ex., dependência da memória autobiográfica), o fato de as entrevistas terem sido realizadas em grupo pode ter gerado constrangimentos para os participantes no que se refere às vivências da sexualidade, explicando os escores menos expressivos nas tarefas relacionadas ao gênero.

Assim, recomenda-se, evidentemente, que sejam realizadas pesquisas sobre TD com amostras mais representativas e com outros delineamentos. Não obstante, assinala-se que esta pesquisa contribui para a literatura científica brasileira tanto por abordar um autor relevante em Psicologia do Desenvolvimento, que tem poucos textos a seu respeito em língua portuguesa, quanto por apresentar uma proposta de compreensão do curso de vida em praticamente toda sua extensão.

\section{Referências}

Baltes, P. B. (1987). Theoretical propositions of Life-Span developmental psychology: On the dynamics betwen growth and decline. Developmental Psychology, 5, 611-626.

Freund, A. M. (2001). Developmental psychology of life-management. In N. J. Smelser \& P. B. Baltes (Eds.), International encyclopedia of the behavioral and social sciences (Vol. 13, pp. 8827-8832). Oxford, UK: Elsevier Science.

Gauer, G., \& Gomes, W. B. (2008). Recordação de eventos pessoais: Memória autobiográfica, consciência e julgamento. Psicologia: Teoria e Pesquisa, 24(4), 507-514.

Glat, R., Santos, R. S., Pletsch, M. D., Nogueira, M. L. L., \& Duque, M. A. F. T. (2004). O método de história de vida na pesquisa em educação especial. Revista Brasileira de Educação Especial, 10, 235-250.

Havighurst, R. J. (1953). Human development and education. New York: Longmans.

Havighurst, R. J. (1956). Research on the developmental-task concept. The School Review, 64(5), 215-223.

Instituto Brasileiro de Geografia e Estatística. (2010). Estatísticas do registro civil. Recuperado em 10 de janeiro, 2012, de www.ibge.gov.br

Josselson, R. (2009). The present of the past: Dialogue with memory over time. Journal of Personality, 77(3), 647-668.

Krings, F., Bangerter, A., Gomez, V., \& Grob, A. (2008). Cohort differences in personal goals and life satisfaction in young adulthood: Evidence for historical shifts in developmental tasks. Journal of Adult Development, 15, 93-105.

Junqueira, M. L. (2010). Maturidade para a escolha da carreira em adolescentes de um serviço de orientação profissional (Tese de mestrado, Departamento de Psicologia e Educação, Universidade de São Paulo, Ribeirão Preto, SP, Brasil). 
Freitas, E. R., Barbosa, A. J. G., Scoralick-Lempke, N., Magalhães, N. C., Vaz, A. F. C., Daret, C. N., Peres, F. S. \& Carvalho, M. F. (2013). Tarefas de Desenvolvimento e História de Vida de Idosos: Análise da Perspectiva de Havighurst.

Magalhães, M. O., \& Gomes, W. B. (2005). Personalidades vocacionais, generatividade e carreira na vida adulta. Revista Brasileira de Orientação Profissional, 6(2), 71-79.

Maniar, A., \& Joshi, U. (2010). Influence of television viewing on the developmental tasks of elderly. Asian Journal of Home Science, 5(1), 207-211.

Martins, P. O., Trindade, Z. A., \& Almeida, A. M. O. (2003). $\mathrm{O}$ ter e o ser: Representações sociais da adolescência entre adolescentes de inserção urbana e rural. Psicologia: Reflexão e Crítica, 16(3), 555-568.

Neri, A. L. (2006). O legado de Paul B. Baltes à psicologia do desenvolvimento e do envelhecimento. Temas em Psicologia, 14(1), 17-34.

Papalia, D. E., Olds, S. W., \& Feldman, R. D. (2010). Desenvolvimento humano (10. ed.). Porto Alegre, RS: AMGH.

Perucchi, J. (2009). Dos estudos de gênero às teorias Queer: Desdobramentos do feminismo e do movimento LGBT na psicologia social. In Anais do XV Encontro Nacional da Associação Brasileira de Psicologia Social (pp. 1-5). Maceió, AL: Associação Brasileira de Psicologia Social.

Pfeiffer, J. P., \& Pinquart, M. (2011). Attainment of developmental tasks by adolescents with and without visual impairment Journal of Visual Impairment and Blindness, 105, 33-45.

Pimenta, M. M. (2007). “Ser jovem” e "ser adulto”: Identidades, representações e trajetórias (Tese de doutorado em Sociologia, Faculdade de Filosofia, Letras e Ciências Humanas, Universidade de São Paulo, SP, Brasil).

Pinquart, M., Silbereisen, R. K., \& Wilesner, M. (2004). Changes in discrepancies between desired and present states of developmental tasks in adolescence: A 4-process model. Journal of Youth and Adolescence, 33(6), 467-477.

Roisman, G. I., Masten, A. S., Coatsworth, J. D., \& Tellegen, A. (2004). Salient and emerging developmental tasks in the transition to adulthood. Child Development, 75, 1-11.

Scoralick-Lempke, N. N. (2009). Alfabetização digital: Aprendizagem e utilização do computador na velhice (Dissertação de mestrado, Programa de Pós-Graduação em Psicologia, Universidade Federal de Juiz de Fora, MG, Brasil).

Shaffer, A., Burt, K. B., Obradović, J., Herbers, J. E., \& Masten, A. S. (2009). Intergenerational continuity in parenting quality: The mediating role of social competence. Developmental Psychology, 45, 1227-1240.

Shaffer, D. R., \& Kipp, K. (2012). Psicologia do desenvolvimento: Infância e adolescência (2. ed.). São Paulo, SP: Cengage Learning.

Silva, A. P., Barros, C. R., Nogueira, M. L. M., \& Barros, V. A. (2007). "Conte-me sua história": Reflexões sobre o método história de vida. Mosaico: Estudos em Psicologia, 1(1), 25-35.

Witter, G. P. (2006). Tarefas de desenvolvimento do adulto idoso. Estudos de Psicologia (Campinas), 23(1), 13-18. 